\title{
Treatment of a dislocated lens by transcorneal vitrectomy and bimanual phacoemulsification
}

\author{
This article was published in the following Dove Press journal: \\ Clinical Ophthalmology \\ 18 August 2014 \\ Number of times this article has been viewed
}

\section{Akira Watanabe \\ Tamaki Gekka \\ Hiroshi Tsuneoka}

Department of Ophthalmology, The jikei University School of Medicine, Tokyo, Japan
Correspondence: Akira Watanabe Department of Ophthalmology, The jikei University School of Medicine, 3-25-8 Nishi-shinbashi, Minato-ku, Tokyo, 105-846I, Japan

Tel +8 I 33433 | I I |

Fax +81334331936

Email akirawa@jikei.ac.jp
Background: As a method of treatment for a dropped lens nucleus, which occurred during cataract surgery, the dropped lens nucleus was removed through the corneal wound without using pars plana vitrectomy (PPV). After vitrectomy, the dropped lens nucleus was floated on the perfluorocarbon liquid (PFCL). The floating lens nucleus was then phacoemulsified and aspirated. During surgery, irrigation from the anterior chamber was performed. This method was very effective for treatment of a dropped hard nucleus.

Case report: During cataract surgery on the left eye of an 80-year-old woman, a posterior capsule rupture occurred. As a result, the lens nucleus dropped into the vitreous cavity. Irrigation to the anterior chamber was performed, with an anterior chamber maintainer inserted through a newly created side port at the corneal limbus. A vitreous cutter and a light guide were inserted in order to perform vitrectomy through the corneal incisions that were created for the cataract surgery. After vitrectomy, the dropped lens nucleus was floated using PFCL. The floating lens nucleus was removed by a bimanual phacoemulsification technique, with the anterior chamber irrigation continuing. The separation of the irrigation port and the aspiration port allowed for effective treatment of the dropped nucleus that was floating on the PFCL, even using a phacoemulsification machine with a peristaltic pump system. Safe and effective vitrectomy, similar to a PPV, could be performed with this method using three corneal ports.

Conclusion: This technique may allow safer and more effective treatment for a dropped lens nucleus compared with conventional PPV. With this technique, corneal distortion due to surgical manipulation can lead to reduced visibility of the posterior eye.

Keywords: dislocated lens, transcorneal vitrectomy, bimanual phacoemulsification

\section{Introduction}

If the posterior capsule ruptures during cataract surgery, the lens nucleus may drop into the vitreous cavity. To retrieve a dropped lens nucleus, pars planar vitrectomy (PPV) is usually performed. ${ }^{1,2}$ For treatment in the vitreous cavity, a vitreous cutter is often used, along with a fragmatome if the nucleus is hard.

A decade has passed since $25 \mathrm{G}$ transconjunctival microincisional vitreous surgery (MIVS) was first reported in 2002, ${ }^{3}$ and the use of MIVS has since expanded in Japan.

Therefore, MIVS is now being performed in cases of a dropped lens nucleus that may occur as a complication of cataract surgery. ${ }^{4}$ However, problems may occur when trying to retrieve a dropped lens using a technique similar to the conventional $20 \mathrm{G}$ PPV. A new scleral incision and trocar placement are necessary in PPV by MIVS. In many facilities, because a fragmatome is $20 \mathrm{G}$ for, for a hard lens nucleus, the dropped lens nucleus is floated on perfluorocarbon liquid (PFCL) and phacoemulsification is often performed as a treatment. ${ }^{5,6}$ 
This case report demonstrates favorable results that were obtained using transcorneal vitrectomy and anterior chamber irrigation for a patient with dislocation of the lens nucleus into the vitreous cavity during cataract surgery.

\section{Case report}

The patient was an 80-year-old woman with a progressive cataract in the left eye (Emery-Little classification: grade 4 nucleus). In the left eye, the corrected distance visual acuity (CDVA) was +1.6 logMAR and corneal astigmatism was $-1.75 \mathrm{D}$. The preoperative number of corneal endothelial cells was 2,571 cells $/ \mathrm{mm}^{2}$ in the right eye and 2,653 cells $/ \mathrm{mm}^{2}$ in the left eye. The patient's past medical history was unremarkable.

During cataract surgery for the left eye, posterior capsule rupture occurred. As a result, part of the lens nucleus dropped into the vitreous cavity. Anterior vitrectomy and removal of residual cortex from the lens capsule for lens dislocation with posterior capsule rupture were performed by two-way divided irrigation and aspiration using a corneal side port.

\section{Transcorneal vitrectomy}

Irrigation to the anterior chamber was then performed with an anterior chamber $(23 \mathrm{G})$ maintainer inserted through a newly created side port at the corneal limbus (Figure 1A). A vitreous cutter $(23 \mathrm{G})$ and light guide $(23 \mathrm{G})$ were inserted to perform vitrectomy through the corneal incisions created for cataract surgery (Figure 1B and 1C).

\section{Phacoemulsification of dropped lens floated on PFCL}

After vitrectomy, the dropped lens nucleus was floated on PFCL (Figure 2A and 2B). The floating lens nucleus was removed using a bimanual phacoemulsification technique while anterior chamber irrigation continued (Figure $2 \mathrm{~B}$ and $2 \mathrm{C}$ ). Due to the convex shape of the PFCL interface (Figure $3 \mathrm{~A})$, the lens fragment was unable to be visualized below the iris. However, it was able to be located by changing the direction of the infusion port and the fluid stream into the eye (Figure 3B).

The PFCL was removed, peripheral vitrectomy with scleral depression was performed, and the lens cortex entangled in the peripheral vitreous was removed. The intraocular lens was secured in the ciliary sulcus and the wound was closed. Mydriasis was maintained throughout the surgery.

\section{Postoperative course}

At 1 month postoperative, the CDVA was $+0.3 \log$ MAR with $-2.75-2.25 \mathrm{D} \times 120$ and the intraocular pressure (IOP) was $14 \mathrm{mmHg}$. At 2 months postoperative, the CDVA was $+0.1 \log$ MAR with $-2.00-2.00 \mathrm{D} \times 120$ and the IOP was $14 \mathrm{mmHg}$. Further, the cornea was maintained as compared with preoperative, with a corneal endothelial cell number of $2,604 / \mathrm{mm}^{2}$ and corneal astigmatism of $-1.75 \mathrm{D}$.

\section{Discussion}

MIVS with $23 \mathrm{G}$ and $25 \mathrm{G}$ vitrectomy systems is increasingly being performed for vitreoretinal diseases. If a lens nuclear fragment drops into the vitreous cavity due to posterior capsule rupture as a complication of cataract surgery, MIVS can be performed to retrieve the fragment. ${ }^{4}$ To retrieve a dropped nuclear fragment by PPV with MIVS, a new scleral incision and trocar placement are necessary. However, when a cataract surgery incision is enlarged to treat posterior capsule rupture, trocar placement may be difficult due to ocular hypotension or incision leakage during trocar/cannula insertion. In addition, vitreous incarceration in the scleral incision can lead to postoperative complications. Wang et $\mathrm{al}^{7}$ reported insertion of
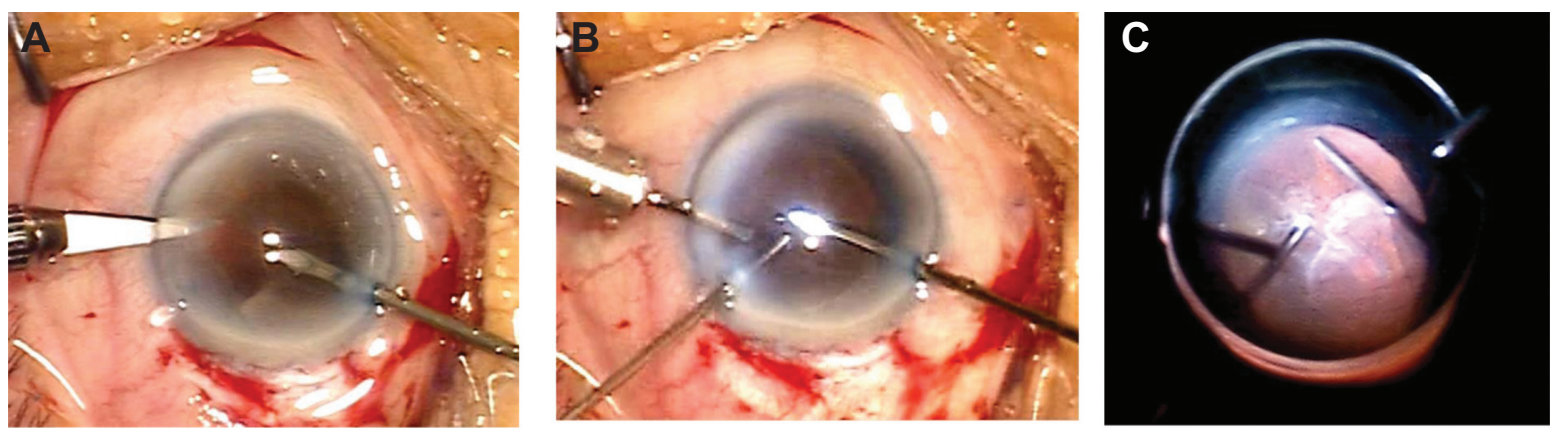

Figure I Transcorneal vitrectomy.

Notes: (A) Irrigation to the anterior chamber was performed with an anterior chamber $(23 \mathrm{G})$ maintainer inserted through a newly created side port at the corneal limbus. (B, C) A vitreous cutter ( $23 \mathrm{G})$ and light guide $(23 \mathrm{G})$ were inserted to perform vitrectomy through the corneal incisions created for cataract surgery. 

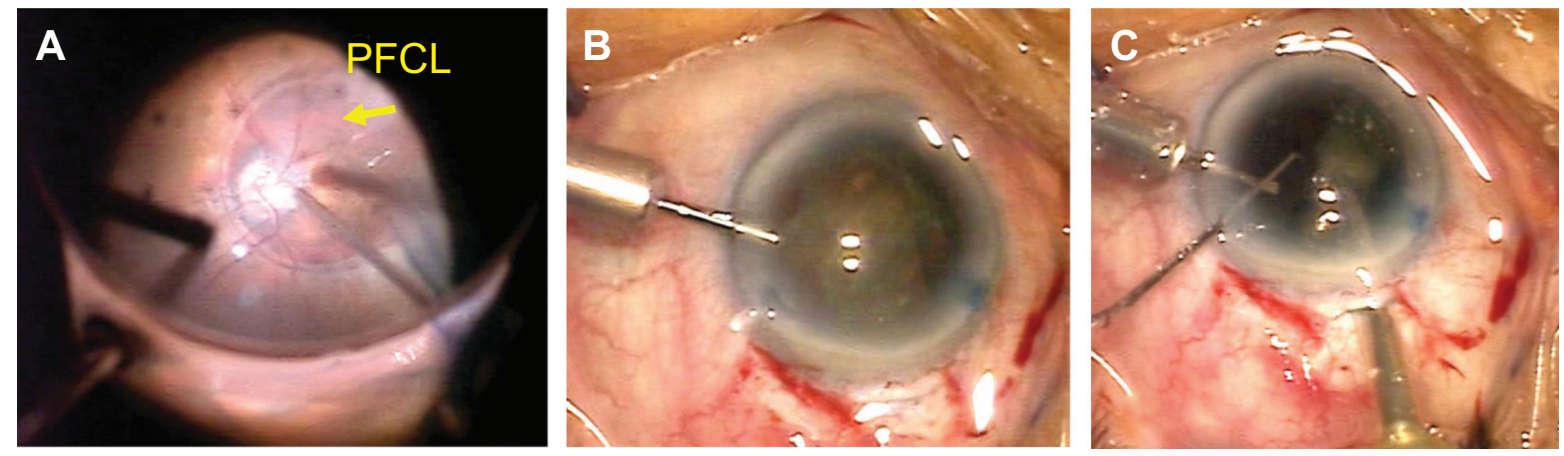

Figure 2 Phacoemulsification of dropped lens floated on perfluorocarbon liquid (PFCL).

Notes: (A) Lens nuclear fragment floated on PFCL (arrow). (B) After vitrectomy, the dropped lens nucleus was floated on PFCL. Infusion from cannula. (C) Phacoemulsification of dropped lens floated on PFCL. The floating lens nucleus was removed by a biaxial phacoemulsification technique while anterior chamber irrigation continued. Infusion was not performed using an ultrasonic handpiece.

a $20 \mathrm{G}$ vitreous cutter and light pipe through the corneal layer to remove a dropped lens nuclear fragment in the vitreous cavity, as a complication of cataract surgery. They reported that when the dropped nuclear fragment comprises less than half of the lens, even if the lens is hard, it can be crushed with a light pipe and vitreous cutter. Nakasato et $\mathrm{al}^{8}$ reported on a method of removing dislocated nuclear fragments, smaller than one-quarter of the size of the lens nucleus, through the sclerocorneal incision made for the cataract surgery. An anterior vitreous cutter with a $27 \mathrm{G}$ chandelier endoilluminator tied to its sleeve was inserted into the eye through the incision made for cataract surgery and used for core vitrectomy. A fragmatome with another $27 \mathrm{G}$ chandelier endoilluminator fiber was used to grasp and move the larger dislocated nuclear fragments into the anterior chamber, where they were divided and removed.

When a nuclear fragment with grade 4 hardness (EmeryLittle classification) drops into the vitreous cavity, removal

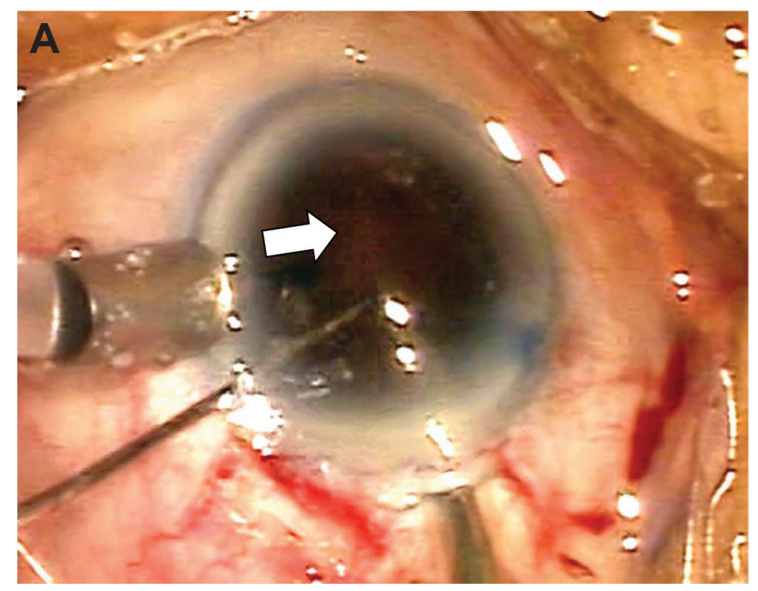

using a $25 \mathrm{G}$ vitreous cutter alone is difficult. In $20 \mathrm{G}$ vitrectomy, a $20 \mathrm{G}$ fragmatome can be inserted into the vitreous cavity through a scleral incision, and the nucleus in the vitreous cavity can be removed using ultrasound., ${ }^{1,2}$ However, fragmatomes that can be inserted from $23 \mathrm{G}$ and $25 \mathrm{G}$ cannulas are not yet widely available. Removing the nuclear fragments in the vitreous cavity by ultrasound, is thus not always possible. Therefore, to retrieve a hard nuclear fragment, PFCL must be injected into the vitreous cavity after vitrectomy, the nuclear fragment floated up to the iris, and the nuclear fragment on the PFCL removed using a phacoemulsification handpiece.

The shape of the interface between the PFCL and aqueous is convex, so nuclear fragments floated on the PFCL may be hidden by the iris. Because the space above the PFCL is wider compared with the lens capsule, freedom of movement of nuclear fragments is greater than with phacoemulsification in the capsule. This makes collection on the

Figure 3 Phacoemulsification of the dropped lens floated on perfluorocarbon liquid (PFCL). The direction of the infusion is indicated by the arrows.

Notes: (A) The lens fragment could not be visualized below the iris because of the convex shape of the PFCL interface. (B) By changing the direction of the infusion port and fluid stream into the eye, the lens nuclear fragment was able to be located. The lens nuclear fragment that had been hidden by the iris exits from the fluid stream. 
phacoemulsification of the tip more difficult. By creating a fluid stream with irrigation and aspiration, nuclear fragments can be efficiently collected on the phacoemulsification of the tip. The fluid stream can be changed by divided irrigation and aspiration (bimanual phacoemulsification). ${ }^{9}$ By changing the fluid stream, nuclear fragments hidden by the iris can be identified.

Implementing vitreous treatment from the corneal incision, with transcorneal vitrectomy, vitreous incarceration into the corneal incision can easily be recognized, and port problems can be prevented. ${ }^{7}$ The incision is the same for cataract surgery or anterior vitrectomy, so surgical invasiveness can be reduced. If an incision is enlarged when a lens dislocation occurs, the IOP cannot be maintained and a trocar puncture may be difficult. The procedure reported in this case study does not require a trocar and is effective in cases of lens dislocation. If a vitreous cutter and light pipe are compressed by a floating lens and irrigating hand-held lens system, corneal distortion can lead to reduced visibility.

\section{Conclusion}

In conclusion, transcorneal vitrectomy and bimanual phacoemulsification are useful for a dropped lens floated on PFCL, when the nucleus is hard and cannot be treated using a vitreous cutter.

\section{Disclosure}

The authors report no conflicts of interest in this work.

\section{References}

1. Rofagha S, Bhisitkul RB. Management of retained lens fragments in complicated cataract surgery. Curr Opin Ophthalmol. 2011;22(2): 137-140.

2. Ho LY, Doft BH, Wang L, Bunker CH. Clinical predictors and outcomes of pars plana vitrectomy for retained lens material after cataract extraction. Am J Ophthalmol. 2009;147(4):587-594.

3. Fujii GY, De Juan E Jr, Humayun MS, et al. A new 25-gauge instrument system for transconjunctival sutureless vitrectomy surgery. Ophthalmology. 2002;109(10):1807-1812.

4. Baker PS, Spirn MJ, Chiang A, et al. 23-Gauge transconjunctival pars plana vitrectomy for removal of retained lens fragments. Am J Ophthalmol. 2011;152(4):624-627.

5. Jang HD, Lee SJ, Park JM. Phacoemulsification with perfluorocarbon liquid using a 23-gauge transconjunctival sutureless vitrectomy for the management of dislocated crystalline lenses. Graefes Arch Clin Exp Ophthalmol. 2013;251(5):1267-1272.

6. Lee SJ, Kim IG, Park JM. Management of posteriorly dislocated crystalline lens with perfluorocarbon liquid and fibrin glue-assisted scleralfixated intraocular lens implantation. J Cataract Refract Surg. 2013; 39(3):334-338.

7. Wang ZY, Zhao K, Li JK, Biswal M, Zhao PQ. Immediate corneal vitrectomy for posteriorly dislocated lens fragments during cataract surgery. Retina. 2013;33(8):1715-1719.

8. Nakasato H, Uemoto R, Kawagoe T, Okada E, Mizuki N. Immediate removal of posteriorly dislocated lens fragments through sclerocorneal incision during cataract surgery. Br J Ophthalmol. 2012;96(8): $1058-1062$.

9. Tsuneoka H, Shiba T, Takahashi Y. Feasibility of ultrasound cataract surgery with a $1.4 \mathrm{~mm}$ incision. J Cataract Refract Surg. 2001;27(6): 934-940.
Clinical Ophthalmology

\section{Publish your work in this journal}

Clinical Ophthalmology is an international, peer-reviewed journal covering all subspecialties within ophthalmology. Key topics include: Optometry; Visual science; Pharmacology and drug therapy in eye diseases; Basic Sciences; Primary and Secondary eye care; Patient Safety and Quality of Care Improvements. This journal is indexed on Submit your manuscript here: http://www.dovepress.com/clinical-ophthalmology-journal

\section{Dovepress}

PubMed Central and CAS, and is the official journal of The Society of Clinical Ophthalmology (SCO). The manuscript management system is completely online and includes a very quick and fair peer-review system, which is all easy to use. Visit http://www.dovepress.com/ testimonials.php to read real quotes from published authors. 